\title{
Comparison of three serological tests for the detection of Coxiella burnetii specific antibodies in European wild rabbits
}

\author{
Charles Caraguel $^{1 \dagger}$, Sarah Bassett ${ }^{1 \dagger}$, David González-Barrio ${ }^{2}$, Peter Elsworth ${ }^{3}$ and Anne-Lise Chaber ${ }^{1 *}$ (D)
}

\begin{abstract}
Background: Coxiella burnetii causes Q fever, a zoonotic bacterial disease with a multi-host cycle and reservoirs in wild and domestic animal species. Q fever has a significant impact on the Australian public health and economy but its ecology and contributing reservoir species remain poorly understood. In Europe, rabbits (Oryctolagus cuniculus) were identified as a major reservoir of $C$. burnetii and it is possible that they play a similar role in Australia. In absence of commercial kit available for rabbit, the Thermo Fisher - PrioCHECK ${ }^{\mathrm{TM}}$ Ruminant Q fever Ab Plate Kit was adapted to successfully screen rabbits population in Europe. However, this assay is not accessible in Australia and we assessed the equivalency of two commercially available kits in Australia - IDEXX - CHEKIT Q Fever Antibody ELISA kit and IDVet - ID Screen ${ }^{\circledR}$ Q Fever Indirect Multi-species with the Thermo Fisher kit (reference kit).

Results: A total of 94 rabbit sera were screened by all three ELISA kits using the same confirmed positive and negative controls. While the IDEXX kit failed to agree the other two assays (concordance correlation coefficient, $\left.r_{b}<0.77\right)$, IDVet kit showed satisfactory equivalency with Thermo Fisher $\left(r_{b}=0.927\right)$.

Conclusion: IDvet kit provides the best alternative for Thermo Fisher in the detection of $C$. burnetii specific antibodies in rabbits in Australia. Further trials are required to confirm these preliminary results due to the low seroprevalence of Coxiella burnetii observed in the study sera.
\end{abstract}

Keywords: Coxiella burnetii, Q fever, ELISA, Serology, European rabbit, Oryctolagus cuniculus

\section{Background}

Coxiella burnetii is the cause of $\mathrm{Q}$ fever or coxiellosis, a zoonotic bacterial disease of public health significance. The life cycle of the C. burnetii include a wide range of host animal species, commonly farm livestocks, which act as reservoirs, transmitting the disease by shedding the bacterium into the environment. C. burnetii infections in cattle, sheep and goats are ususally asymptomatic but can cause production losses including abortions, infertility, still births, weak offsprings, metritis, mastitis

\footnotetext{
* Correspondence: anne-lise.chaber@adelaide.edu.au

${ }^{+}$Charles Caraguel and Sarah Bassett are co-first authors.

'School of Animal and Veterinary Sciences, The University of Adelaide, Roseworthy, South Australia

Full list of author information is available at the end of the article
}

and other reproductive disorders [1,2]. C. burnetii can be shed in the urine, faeces, placental material and milk of infected animals [3]. The organism can persist in the environment in a spore-like form for several months increasing the likelihood of infection of a new host [4]. Heavy rainfall and high winds speeds have been thought to cause the spores to aerosolise facilitating air-bourne spread and infections through inhalation [5]. The bacterium is highly resistant to desiccation, high temperatures, disinfectants, radiation, ultraviolet light, pressure and oxidative or osmotic stress [4]. In humans, Q fever is more common in professions with close contact with livestocks or processing animal products such as farmers, abattoir workers and veterinarians [4]. In its chronic form, human $\mathrm{Q}$ fever may include respiratory

(c) The Author(s). 2020 Open Access This article is licensed under a Creative Commons Attribution 4.0 International License, which permits use, sharing, adaptation, distribution and reproduction in any medium or format, as long as you give appropriate credit to the original author(s) and the source, provide a link to the Creative Commons licence, and indicate if changes were made. The images or other third party material in this article are included in the article's Creative Commons licence, unless indicated otherwise in a credit line to the material. If material is not included in the article's Creative Commons licence and your intended use is not permitted by statutory regulation or exceeds the permitted use, you will need to obtain permission directly from the copyright holder. To view a copy of this licence, visit http://creativecommons.org/licenses/by/4.0/ The Creative Commons Public Domain Dedication waiver (http://creativecommons.org/publicdomain/zero/1.0/) applies to the data made available in this article, unless otherwise stated in a credit line to the data. 
tract infections, headaches, pyrexia, abortion, hepatitis, osteoarticular infections and endocarditis $[2,6]$.

In Australia, where C. burnetii was first isolated, Q fever is endemic and has a significant health and economic impact on the farming community [7]. Past studies identified macropods as a significant wildlife reservoir of C. burnetii in Australia with seroprevalences up to $30 \%$ [8]. Other documented reservoir hosts in Australia include bandicoots, kangaroos, possums, cats (feral and domestic) and dogs (wild and domestic) as well as arthropod vectors such as ticks [1].

In Europe, González-Barrio et al. reported European wild rabbits (Oryctolagus cuniculus) as a major reservoir [9]. Rabbits can develop systemic C. burnetii infections and females actively shed the bacterium into the environment through vaginal secretions. Rabbits are highly fecund and have unrestricted movement allowing them to spread the disease over vast areas. The European wild rabbit inhabits agricultural land throughout Australia. As such, rabbits may possilbly be another important reservoir of C. burnetii in Australia.

Because of the transient nature of C. burnetii infection and shedding, serology is commonly used to detect infections and prior exposure to C. burnetii in animal studies. However, serological kits commercially available were developed for humans and ruminants and were not intended to detect $C$. burnetii specific antibodies in rabbits. A modified version of the Enzyme-Linked Immunosorbent Assay (ELISA) Thermo Fisher - PrioCHECK ${ }^{\mathrm{mm}}$ Ruminant $\mathrm{Q}$ fever Ab Plate Kit has been successfully implemented in Europe to screen wild rabbit populations [9], however, this test kit is not accessible in Australia. Therefore, this study aimed at testing the equivalency of two ELISA kits commercially available in Australia, the IDEXX - CHEKIT Q Fever Antibody ELISA kit and the IDVet - ID Screen ${ }^{\circ} \mathrm{Q}$ Fever Indirect Multi-species to the Thermo Fisher's kit when detecting $C$. burnetii specific antibodies in rabbits.

\section{Results}

From a study set of 94 rabbit sera, one did not yield a valid Optical Density (OD) reading for the IDEXX kit. The positive control yielded ODs of 3.129, 2.639 and 2.890 , and the negative control had ODs of $0.312,0.379$ and 0.254 for Thermo Fisher, IDEXX and IDVet kit respectively. Following the same test order, sample ODs ranges (minimum-maximum) were 0.057-3.127, 0.1412.287 and $0.052-2.907$, and the sample-to-positive ratio $(\mathrm{S} / \mathrm{P})$ ranges were $-0.091-0.999,-0.105-0.844$ and 0.067-1.006. The IDEXX $S / P$ values showed moderate concordance (concordance correlation coefficient $<0.77$ ) and a strong deviation from identity (regression slope much different from ' 1 ') when compared to the others two ELISA kits (Table 1, Fig. 1a and b). The IDVet kit, however, had excellent concordance with the reference kit, Thermo Fisher, and proximated identity (regression slope $=1.02)$ except for a slight tendency for higher $\mathrm{S} / \mathrm{Ps}$ (regression intercept $=0.056)($ Table 1, Fig. 1c).

\section{Discussion}

We found that the IDVet kit provides equivalent readings to Thermo Fisher's assay and is a satisfactory alternative to detect $C$. burnetii specific antibodies in rabbits. However, the IDEXX kit failed to reproduce the results of the reference assay and we recommend not using this kit to screen rabbits until further refinements are completed.

The use of S/P cutoff values to categorise the ELISA readings would have unlikely change these conclusions. In absence of accepted S/P cutoff values for rabbits serology, we explore a potential impact using the manufacturers' $\mathrm{S} / \mathrm{P}$ cutoffs set for ruminants $-\mathrm{S} / P \geq 0.4$ as seropositive, $\mathrm{S} / P \geq 0.3$ and $<0.4$ as borderline and $\mathrm{S} / P<$ 0.3 as seronegative (Fig. 1). The IDEXX kit results would included only one seropositive serum and another one borderline, both of which were strong positive (highest S/Ps) with the Thermo Fisher and IDVet assays (Fig. 1a and $b)$. On the other hand, the IDVet kit showed satisfactory agreement with the Thermo Fisher kit, except two samples classified as borderline by one of the two assays (Fig. 1c). Compare to the other assays, the S/Ps from the IDEXX kit were substantially weaker in both absolute (OD) and relative (S/P) terms. IDVet had slightly and systematically higher S/Ps than Thermo Fisher but this did not affect their agreement. This is potentially explained by an assumed higher affinity for pathogen specific antibody binding of the IDVet's

Table 1 Pearson's correlarion coefficient $(r)$, bias-corretion factor $\left(C_{b}\right)$, concordance correlation coefficient $\left(r_{b}=r \times C_{b}\right)$, reduced major axis slope and intercept estimates for each pairwise comparison of sample-to-positve ratios between CHEKIT Q Fever Antibody ELISA kit (IDEXX), ELISA kits - PrioCHECK ${ }^{\text {TM }}$ Ruminant Q fever Ab Plate Kit (Thermo Fisher) and ID Screen ${ }^{\circledast}$ Q Fever Indirect Multi-species (IDvet)

\begin{tabular}{|c|c|c|c|c|c|}
\hline Pairwise comparisons & $\begin{array}{l}\text { Pearson's correlarion } \\
\text { coefficient }(r)\end{array}$ & $\begin{array}{l}\text { Bias-correction } \\
\text { factor }\left(C_{b}\right)\end{array}$ & $\begin{array}{l}\text { Concordance correlation } \\
\text { coefficient }\left(r_{b}=r \times C_{b}\right)\end{array}$ & Regression slope & $\begin{array}{l}\text { Regression } \\
\text { intercept }\end{array}$ \\
\hline IDEXX vs. Thermo Fisher & 0.883 & 0.871 & 0.769 & 0.594 & -0.030 \\
\hline IDvet vs. Thermo Fisher & 0.969 & 0.957 & 0.927 & 1.021 & 0.056 \\
\hline IDEXX vs. IDvet & 0.844 & 0.776 & 0.654 & 0.582 & -0.062 \\
\hline
\end{tabular}




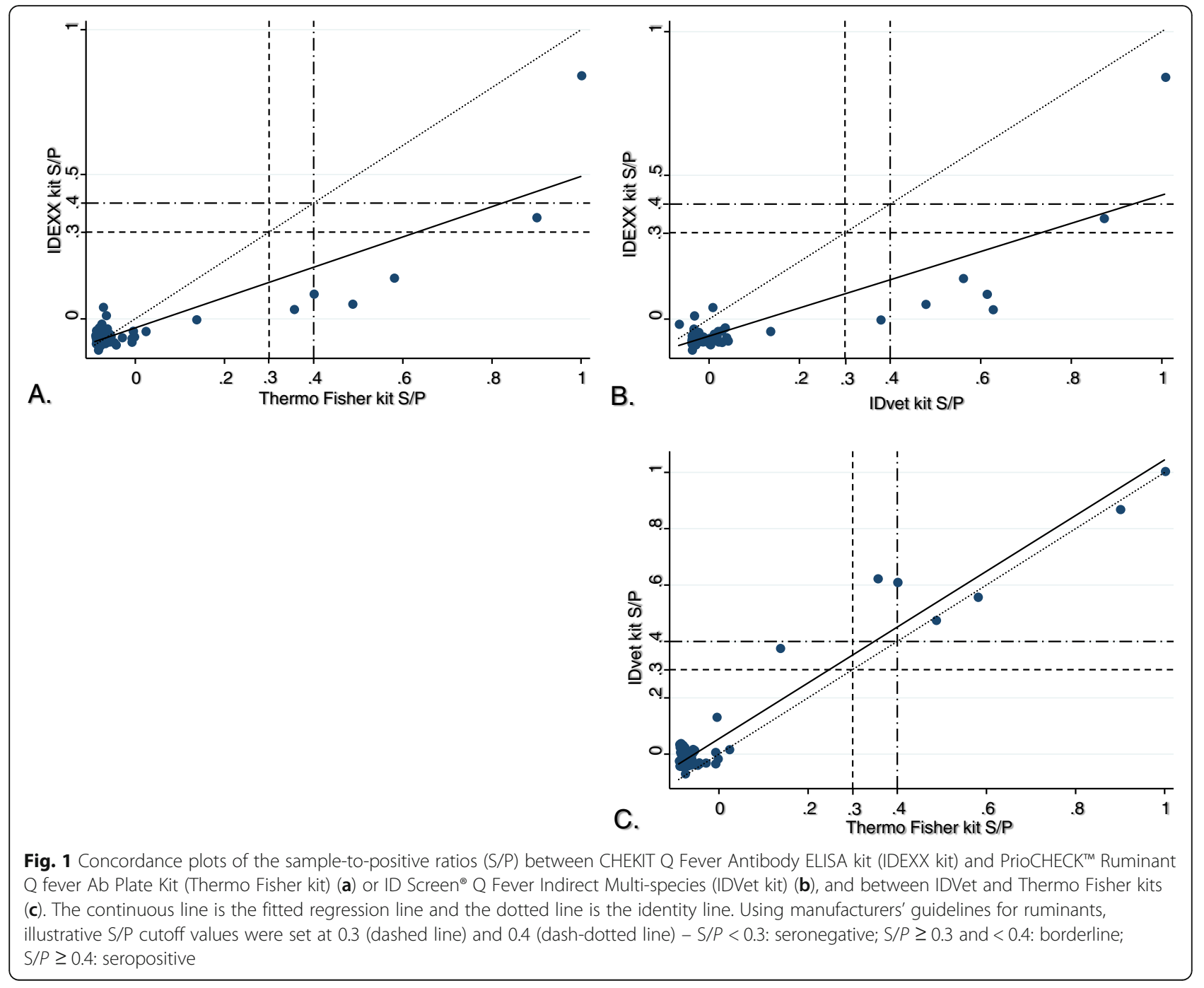

conjugate compared to the protein $\mathrm{G}$ horseradish peroxidase used in the IDEXX and Thermo Fisher assays.

The seroprevalence in the study set of sera appeared low with only seven to eight samples out of $94(<10 \%)$ with higher S/P (Fig. 1). Increasing the proportion of seroconverted rabbits in the testing pool would provide a better coverage of the range of antibody titres and potentially a more comprehensive estimate of the assays' equivalency.

\section{Conclusions}

We found that the IDVet kit provides equivalent readings to Thermo Fisher's assay and is a satisfactory alternative to detect $C$. burnetii specific antibodies in rabbits. However, the IDEXX kit failed to reproduce the results of the reference assay and we recommend not using this kit to screen rabbits until further refinements are completed.

\section{Methods}

\section{Source and testing of rabbit sera}

Between 2007 and 2017, the Australian Department of Agriculture and Fisheries survey rabbit from eight locations across Queensland for other reasons than Q fever screening. Collected sera were archived and made accessible for subsequent research. A subset of 192 sera were purposively selected to cover all eight locations in absence of any $\mathrm{Q}$ fever history. The samples were first individually screened using PrioCHECK ${ }^{\mathrm{m}}$ Ruminant $\mathrm{Q}$ fever Ab Plate Kit (Thermo Fisher, Life Technologies, Carlsbad, CA, USA) at our partner laboratory in Spain following a modified protocol for rabbit testing using a Protein G conjugate as described elsewhere [9]. Positive and negative controls were provided by the Spanish Wildlife Research Institute [9]. The positive control were sera from naturally infected rabbits confirmed with the presence of C. burnetii DNA by Polymerase Chain Reaction (PCR) in both spleen and vaginal swabs and the 
presence of antibodies against $C$. burnetii with a high Optical Density (OD) with ELISA [9]. Given the successful implementation of the Thermo Fisher kit in wild rabbit, including confirmed standards, we consider this kit as our reference assay.

Based on the Thermo Fisher test results, individual sera with OD readings $>1.0(n=6)$ were selected as well as a random selection of 88 of the remainig sera were selected to fit one ELISA plate and to assess the equivalence of two ELISA kits commercially available in Australia; CHEKIT Q Fever Antibody ELISA kit (IDEXX, Liebefeld-Bern, Switzerland) and ID Screen ${ }^{\circ} \mathrm{Q}$ Fever Indirect Multi-species (IDVet, Montpellier, France). For both tests, the same positive and negative controls as for the Thermo Fisher kit were used.

As for the Thermo Fisher kit, the IDEXX test was modified using a protein $\mathrm{G}$ horseradish peroxidase conjugate (Sigma-Aldrich, St Louis, MO, USA) which has a high affinity for most mammalian Immunoglobulin G (IgG) antibodies. The conjugate acts as a secondary antibody which binds to the Fragment crystallisable (Fc) region of rabbit IgG specific to $C$. burnetii present in the wells after washing. The plate was incubated at $37^{\circ} \mathrm{C}$ following the protocol from IDEXX. The ODs were read at $450 \mathrm{~nm}$ using a microplate reader.

For the IDVet test, the 96 well ELISA plate was run using their multi-species horseradish peroxidase conjugate provided in the kit to trial if it had an affinity for rabbit IgG allowing it to bind. The plates were incubated at $26^{\circ} \mathrm{C}$ and ODs read at $450 \mathrm{~nm}$.

\section{Data analysis}

ODs were converted into a sample-to-positive ratio $(\mathrm{S} / \mathrm{P})$ as follow:

\section{$S / P=\frac{O D \text { sample }-O D \text { negative control }}{\text { OD positive control }- \text { OD negative control }}$}

S/Ps between kits were compared numerically by estimating the concordance correlation coefficient $\left(r_{b}\right)$ which combined the Pearsons's correlation coefficient $(r)$ and the bias-correction factor $\left(C_{b}\right)\left(r_{b}=r \times C_{b}\right)$ and visually by comparing the proximity of the fitted regression line with the identity kine in the concordance correlation plots $[10,11]$. All statistical analyses were performed using the statistical package Stata v15.1 (College Station, StatCorp Ltd., Texas, USA).

\section{Abbreviations}

ELISA: Enzyme-Linked Immunosorbent Assay; PCR: Polymerase Chain Reaction; OD: Optical Density; S/P: Sample-to-positive ratio; Thermo Fisher: PrioCHECK ${ }^{\mathrm{TM}}$ Ruminant Q fever Ab Plate Kit; IDEXX: CHEKIT Q Fever Antibody ELISA kit; IDVet: ID Screen ${ }^{\oplus}$ Q Fever Indirect Multi-species; IgG: Immunoglobulin G; Fc: Fragment crystallisable; $r$ : Pearsons's correlation coefficient; $C_{b}$ : Bias-correction factor; $r_{b}$ : Concordance correlation coefficient

\section{Acknowledgments}

This project was supported by IDVet and IDEXX who donated ELISA kits for the trial with rabbit serum samples. We are very grateful to the Spanish Wildlife Research Institute for providing us with the positive and negative control sera. D. González-Barrio is granted by the Spanish Ministry of Science through a Juan de la Cierva postdoctoral fellow (FJCl-2016-27875). Thanks goes to Michael Brennan and David Berman who assisted in obtaining rabbit samples in the field.

\section{Authors' contributions}

SB performed the IDEXX and IDVet ELISA testing, contributed with data analysis and interpretation and wrote the manuscript. CC performed the data analysis and interpretation and manuscript writing. DGB performed the Thermo Fisher ELISA testing. PE collected and provided the rabbit serum samples from Queensland. ALC designed the study, liased with the from IDEXX and IDVet laboratories, the Complutense University of Madrid and the Department of Agriculture and Fisheries in Queensland. All authors contributed to, read and approved the final manuscript.

\section{Funding}

The Students research fund provided by the School of Animal and Veterinary Sciences of the University of Adelaide (South Australia) covered the

shipment of samples and the laboratory expenses. IDEXX and IDVet donated the ELISA kits used in this study. This project is supported by funding from the Australian Government Department of Agriculture, Water and the Environment as part of its Rural R\&D for Profit program. Funders had no role in the design of the study and collection, analysis, and interpretation of data and in writing the manuscript.

\section{Availability of data and materials}

The study datasets used and/or analysis code are available from the corresponding author upon request.

\section{Ethics approval and consent to participate}

In accordance with local legislation, the samples were collected under the following approvals: Pest Animal Ethics Committee (PAEC) 060601, Community Access Animal Ethics Committee (CA AEC) 2013/07/709 and 2016/07/982. The rabbits from Diamantina Lakes, Whetstone and Townsville were collected under PAEC 060601 and the rest under CA AEC 2013/07/709 and 2016/07/982. The University of Adelaide Animal Ethics Committee approved the use of these samples.

\section{Consent for publication}

The Pest Animal Research Centre, Department of Agriculture and Fisheries, Toowoomba, Queensland, gave consent for their sampled animal's serological results and clinical details to be published in this study.

\section{Competing interests}

The authors declare that they have no competing interests.

\section{Author details}

${ }^{1}$ School of Animal and Veterinary Sciences, The University of Adelaide, Roseworthy, South Australia. ${ }^{2}$ SALUVET, Animal Health Department, Faculty of Veterinary Sciences, Complutense University of Madrid, Ciudad Universitaria s/n, 28040 Madrid, Spain. ${ }^{3}$ Pest Animal Research Centre, Department of Agriculture and Fisheries, Toowoomba, Queensland, Australia.

Received: 30 April 2020 Accepted: 17 August 2020

Published online: 28 August 2020

\section{References}

1. Agerholm JS. Coxiella burnetii associated reproductive disorders in domestic animals-a critical review. Acta Vet Scand. 2013;55(1):13.

2. Garcia-Ispierto I, Tutusaus J, López-Gatius F. Does Coxiella burnetii affect reproduction in cattle? A clinical update. Reprod Domest Anim. 2014;49(4): 529-35.

3. Harris P, Eales KM, Squires R, Govan B, Norton R. Acute Q fever in northern Queensland: variation in incidence related to rainfall and geographical location. Epidemiol Infect. 2013;141(5):1034-8. 
4. Dorko E, Rimárová K, Pilipčinec E. Influence of the environment and occupational exposure on the occurrence of Q fever. Cent Eur J Public Health. 2012;20(3):208.

5. Sivabalan P, Saboo A, Yew J, Norton R. Q fever in an endemic region of North Queensland, Australia: a 10 year review. One Health. 2017;3:51-5.

6. McCaughey C, Murray L, McKenna JP, Menzies FD, McCullough SJ, O'Neill $H J$, Wyatt DE, Cardwell CR, Coyle PV. Coxiella burnetii (Q fever) seroprevalence in cattle. Epidemiol Infect. 2010;138(1):21-7.

7. Garner MG, Longbottom HM, Cannon RM, Plant AJ. A review of Q fever in Australia 1991-1994. Aust N Z J Public Health. 1997;21(7):722-30.

8. Cooper A, Barnes T, Potter A, Ketheesan N, Govan B. Determination of Coxiella burnetii seroprevalence in macropods in Australia. Vet Microbiol. 2012;155(2-4):317-23.

9. González-Barrio D, Maio E, Vieira-Pinto M, Ruiz-Fons F. European rabbits as reservoir for Coxiella burnetii. Emerg Infect Dis. 2015;21(6):1055.

10. Lin L. A concordance correlation coefficient to evaluate reproducibility. Biometrics. 1989;45:255-68.

11. Lin L. A note on theconcordance correlation coefficient. Biometrics. 2000;56: $324-5$.

\section{Publisher's Note}

Springer Nature remains neutral with regard to jurisdictional claims in published maps and institutional affiliations.

Ready to submit your research? Choose BMC and benefit from:

- fast, convenient online submission

- thorough peer review by experienced researchers in your field

- rapid publication on acceptance

- support for research data, including large and complex data types

- gold Open Access which fosters wider collaboration and increased citations

- maximum visibility for your research: over $100 \mathrm{M}$ website views per year

At $\mathrm{BMC}$, research is always in progress.

Learn more biomedcentral.com/submissions 